\title{
TEORÍA DE LAS DESCRIPCIONES, SIGNIFICACIÓN Y PRESUPOSICIÓN
}

El propósito de este artículo es confrontar, en sus grandes líneas, la Teoría de las Descripciones de Russell con la crítica que Strawson hizo de ella, para llegar a establecer, con un mínimo de precisión, los diversos niveles de las objeciones; no intentaremos criticar, a nuestra vez, las doctrinas de Strawson. Para ello comenzaremos haciendo una exposición de la Teoría de las Descripciones que será, en extensión, bastante más amplia que la parte dedicada a Strawson. La razón es, simplemente, que las tesis de Russell son más complejas y desarrolladas que las de Strawson y que las críticas de éste no pueden plantearse si no se sigue con un cierto cuidado la Teoría de las Descripciones. Por lo demás, nuestra exposición de Russell soslayará muchos problemas y dificultades de la Teoría, por no juzgarlos de importancia respecto de los fines de este trabajo. También deseamos dejar en claro que la confrontación se planteará en la perspectiva del lenguaje ordinario. Con lo cual no queremos decir, en manera alguna, que la Teoría de las Descripciones se limite a ese campo. Pero es alli donde surge la polémica con Strawson. Que esto ya de por sí sea una injusticia, es problema aparte. En todo caso hay pruebas suficientes que, cuando menos, Russell no excluye el lenguaje ordinario como zona de aplicación de su teoría. Y, por último, quisiéramos señalar que la doctrina de Strawson acerca de la presuposición sólo la veremos en relación a las descripciones definidas, dejando a un lado sus aplícaciones, por ejemplo, al cuadrado de oposición de la lógica clásica.

I) Quizá no sea exagerado afirmar que los argumentos a los que Russell se opuso con su Teoría de las Descripciones Definidas o Singulares, constituyen un lugar común en la literatura filosófica de nuestros días. No nos demoraremos, por tanto, en un análisis minucioso de ellos, o en una presentación histórica que le hiciera justicia a los matices diversos y a'las variantes de esa tesis central. Simplemente recordaremos aquellos rasgos fundamentales que son necesarios para formular los problemas que nos interesan. ${ }^{1}$

En términos generales, esos argumentos intentan demostrar que es forzoso aceptar ciertos entes si queremos explicar algunos hechos indisputables. Serían los siguientes. En primer lugar, expresiones como "El cuadrado redondo", "La montaña de oro", "El actual Rey de Francia", "La actual Reina

1 No intentaremos, por tanto, precisar hasta qué punto Russell interpreta correctamente a Meinong. Para una exposición de Meinong, véase la obra de J. N. Findlay, Meinong's Theory of Objects and Values, Oxford University Press, segunda edición, 1963. 
de Italia", etc., etc., esto es, expresiones cuya referencia es vacía, son perfectamente significativas consideradas aisladamente; y, en segundo lugar, pueden ser sujetos de proposiciones en las que se predica de ellas y que también son significativas. Nos encontramos, pues, ante expresiones y proposiciones del lenguaje ordinario legítimas desde el punto de vista de la significación. Ahora, si estas expresiones y las proposiciones de las cuales son sujetos son significativas, es menester, se agrega, que se refieran o denoten algo - pues de otro modo no podrían ser significativas. Sin embargo, como venimos de señalar, las expresiones y las proposiciones de las que son sujetos, no se refieren, de hecho, a nada existente: ni en Francia ni en Italia, por ejemplo, hay actualmente reyes, no son monarquías. Si queremos, por tanto, explicar el hecho indudable de su significación, habrá que conceder que, no obstante, se refieren a algo; y es imposible dejar de reconocer que aquello a lo cual se refieren es una entidad. A los efectos de la brevedad, podemos decir que cuando menos es un objeto -cuyo status ontológico podrá, posteriormente, caracterizarse como ideal, lógico, etc. El argumento, entonces, concluye asi: o se refieren $\longrightarrow$ denotan - algo o no son significativas. Puesto que lo son, es necesario asumir, siempre, un denotatum, el cual, dada la naturaleza del caso, tendrá que ser de un tipo lógico, ideal, etc.

Otra forma de argumentar es señalando que si las proposiciones cuyos sujetos son descripciones definidas son significativas - $-\mathrm{y}$ ex hyphotesis lo son- entonces, en razón del principio del tercio excluso, son verdaderas o falsas. Pero una proposición de la forma sujeto-predicado, se añade, es verdadera si el sujeto posee ese atributo y falsa si no lo posee. En ambos casos, la verdad o la falsedad de la proposición implica la existencia del ente al que se refiere el sujeto de la proposición. Por consiguiente, si se aplica el principio del tercio excluso $-y$ se aplica puesto que son significativases menester admitir, siempre, la existencia de aquello a lo cual se refiere el sujeto de la proposición. Pero supongamos que alguien sostiene que la proposición "La montaña de oro no existe" es una proposición de la forma sujeto-predicado —concedámoslo a vía de ejemplo- y que además es verdadera porque no existe espacio-temporalmente una montaña de oro. Si esa persona sostiene, como debería hacerlo según esta linea de razonamiento, que si la proposición es verdadera entonces debe existir aquello a lo cual se refiere el sujeto, se encuentra inmediatamente ante un problema. Porque para que la proposición sea verdadera debe existir el sujeto, pero si existe el sujeto entonces la proposición "La montaña de oro no existe", no es verdadera, es falsa. Caería, pues, en una contradicción: si es verdadera es falsa. Entonces, ¿cómo sostener a la vez que la proposición en cuestión es significativa y, en este caso, verdadera porque espacio-temporalmente no existe una montaña de oro, sin.caer en contradicción? La única manera de conciliar estos hechos es reconociendo que el sujeto "La montaña de oro" se refiere 
a un ente ideal o lógico del cual se dice (se predica) que no existe espaciotemporalmente. Lo cual es verdad. De esta manera cabe mantener que es significativa, que su verdad implica la existencia del sujeto, y que es verdadera porque en el mundo no se encuentra una montaña de oro. $Y$ todo ello sin incurrir en contradicción. Ahora bien, aun en el caso en que se replicara que dicha proposición en manera alguna es de la forma sujeto-predicado, que 'existencia' no es un predicado - la misma dificultad surgiría si se acepta la tesis que afirma que si la expresión "la montaña de oro" es significativa entonces forzosamente denota o refiere. En efecto, al mantener que esa proposición es verdadera porque no hay en el mundo una montaña con esas características, no es posible sostener que su denotación es una montaña de oro que se encuentra en algún lugar del mundo sin. incurrir en una contradicción. De ahí la postulación de un denotatum ideal o lógico. En lo que toca a otros ejemplos, la argumentación que se remite, entre otras cosas, al principio del tercio excluso, parece aplicarse con mayor claridad. Si "El actual Rey de Francia es sabio" es significativa, entonces es verdadera o falsa; lo cual implica que, en ambos casos, existe aquello a lo cual se refiere el sujeto. Pero como hoy día nadie reina en Francia, no es el caso de que la verdad o la falsedad de la proposición implique la existencia espacio-temporal de un individuo. Por tanto, si queremos mantener que es significativa y, por ello, verdadera o falsa, tendremos que reconocer que el sujeto se refiere a un ente ideal ò lógico.

En términos generales se dirá, pues, que parece absurdo negarle toda referencia a esa clase de expresiones. Se admitirá, claro está, que no se refieren a nada que exista espacio-temporalmente, pero parece obvio que, en la medida misma en que son significativas, tienen que referirse a un objeto en particular, tienen que nombrar ese objeto ya que, de lo contrario, no formarian parte del lenguaje. Luego surgirá la necesidad de caracterizarlo desce un punto de vista ontológico; y podrá entonces discutirse qué tipo de entidad es, cuáles son sus propiedades, etc., etc. Pues aun aceptando este modelo de explicación, quedaría un amplio margen de posibles acuerdos y desacuerdos. ${ }^{2}$ Pero por diversas que sean las respuestas a esas preguntas, todas ellas aceptan una entidad como término necesario para explicar la significación de cuando menos esas partes del lenguaje. De modo que, en ambos argumentos, de la significatividad de las expresiones y de las proposiciones de las cuales son sujetos, se pretende demostrar la necesidad de admitir entes ideales o lógicos.

2 Véase, entre otros, el ensayo de Max Black, "Russell's Philosophy of Language", publicado originalmente en el volumen editado por A. Schilpp, The Philosophy of Bertrand Russell, Tudor Publishing Company, tercera edición, 1951. El mismo trabajo se encuentra recogido en el libro de M. Black, Language and Philosophy, Cornell University Press, 1949. 
2) Pasemos, ahora, a la Teoría de las Descripciones. ${ }^{3}$ Hablando con generalidad, podemos decir que Russell intenta dar cuenta de la significación de esas expresiones y proposiciones en forma tal que no sea necesario admitir entes ideales. Pero hay diversas maneras de refutar los argumentos anteriores. Si la postulación de entes ideales se basa, en primer lugar, en una tesis acerca de la significación de esas expresiones y proposiciones, esas inferencias podrian objetarse mostrando que esa teoría de la significación es errónea; en segundo lugar, rechazando la tesis de que si una proposición es significativa entonces es verdadera o falsa. Quede claro, desde ahora, que no es este el camino que sigue Russell en la Teoría de las Descripciones. Otra forma sería aceptar la validez de la tesis acerca de la significación, pero sostener que no se aplica a esta clase de expresiones y a las proposiciones de las cuales son sujetos. Se argumentará, entonces, que el error no se encuentra en la tesis acerca de la significación, sino en el análisis de la forma lógica de esas expresiones y de las proposiciones resultantes -implicándose, claro está, que si tuviesen la forma lógica que suponen los argumentos en contra de los que va la Teoría de las Descripciones, la explicación de su significación debería hacerse de acuerdo con esas tesis; lo cual, nótese, tendría como consecuencia inmediata o la aceptación de entes ideales, o la conclusión de que carecen de significado. Por lo demás, y éste es un punto importante, Russell no rechaza el principio del tercio excluso: las proposiciones cuyos sujetos son descripciones definidas serán siempre, según los casos, verdaderas o falsas. En un sentido amplio, éste es el camino que sigue Russell.

Por consiguiente, lo primero que hay que establecer es que el análisis de la forma lógica de esas expresiones es erróneo; y ello es equivalente a demostrar, para decirlo con máxima brevedad que, por una parte, las descripciones no pueden analizarse como nombres y, por la otra, que las proposiciones de las que son sujetos no tienen la forma de sujeto-predicado, puesto que en ese caso el sujeto debería ser un nombre. Recordemos, un poco de prisa, las razones de Russell. En primer lugar una descripción definida se distinguiría de un nombre por no ser un símbolo simple -el cual se define como un símbolo que carece de partes que a su vez sean símbolos. ${ }^{4} \mathrm{Y}$ la diferencia entre símbolos simples, y descripciones —que son símbolos complejos - se nota en el hecho de que si una determinada persona conoce, por ejemplo, el castellano, de ello no se deriva que conozca el significado de la palabra "Cervantes" - símbolo simple. La suposición de que domina a la perfección el castellano y que, sin embargo, desconoce el significado de "Cervantes", no es contradictoria; fijar el significado de las demás palabras

3 De aquí en adelante por "Teoría de las Descripciones" se entenderá la Teoría de las descripciones definidas. $\mathbf{Y}$ por "Descripciones" se entenderá Descripciones definidas.

4 B. Russell, Introduction to Mathematical Philosophy, Allen and Unwin, novena impresión 1956, pág. 173; Logic and Knowledge, Allen and Unwin, 1956, pág. 244. 
del idioma en nada ayuda a establecer el significado de la palabra "Cervantes". Y ello se debe, según Russell, a que conocer el significado de un nombre es conocer aquello a lo cual se aplica. ${ }^{5}$ Pues de lo contrario, el dominio del idioma implicaría el conocimiento de las personas o cosas a las cuales se refieren los nombres propios de ese lenguaje. Algo absurdo. Con las descripciones, en cambio, no ocurre lo mismo. Si alguien sabe castellano, comprenderá la expresión "El hombre más gordo del mundo"; sería incongruente afirmar que domina el idioma, pero que no sabe qué quiere decir esa expresión. En estos casos, el conocimiento del significado de los símbolos - digámoslo con la misma vaguedad de Russell- que componen esa descripción definida es esencial para su comprensión. ${ }^{6}$ El conocimiento previo del castellano es suficiente. $\mathrm{Y}$ también es bastante claro que dicha comprensión en manera alguna exige, como condición, que sepamos quién es, en verdad, el hombre más gordo del mundo. Otra prueba de la distinción entre nombres y descripciones es la siguiente. Supóngase que en la proposición "Cervantes es el autor del Quijote" se sustituye la descripción definida "El autor del Quijote" por un nombre cualquiera, simbolizado por la letra $c$. Entonces tendríamos lo siguiente: si $c$ es el nombre de alguien que no es Gervantes, la proposición obviamente es falsa; si, en cambio, $c$ designa la misma persona que nombra Cervantes, la proposición se convierte en una tautología. Por el contrario, la proposición "Cervantes es el autor del Quijote" no es ni falsa ni tautológica y, por tanto, no tiene la misma forma que la proposición que se obtiene cuando la descripción es sustituida por un nombre. ${ }^{7}$ Así la identidad que se afirma en la proposición no es tautológica: es una identidad entre un objeto nombrado y un objeto descrito. ${ }^{8} \cdot \mathrm{Si}$ por comodidad quisiera aun emplearse el término sujeto para caracterizar la función que, por ejemplo, cumple " $\mathrm{El}$ autor del Quijote" en la proposición "El autor del Quijote es español", es menester entonces distinguirla con toda pulcritud de la que realiza la palabra "Cervantes" en "Cervantes nació en España". En lo anterior salió a luz, sin dejar lugar a dudas, lo que piensa Russell acerca de la significación de un nombre; si se especifica el objeto del cual es nombre, nada queda por aclarar respecto de su significado. Si un nombre es significativo es posible, por tanto, inferir que existe algo de lo cual es nombre. De ahí que los argumentos en favor de los entes ideales serian válidos para Russell si los sujetos de esas proposiciones fuesen nombres; lo cual indica que acepta, cuando menos para los nombres, la teoría

5 B. Russell, Introduction to Mathematical Philosophy, pág. 174; Logic and Knowledge, pág. 244 .

6 B. Russell, op. cit., pág. 174; op. cit., pág. 244 .

7 B. Russell, op. cit., págs. 174-75; op. cit., págs. 245-46; véase también Principia Mathematica, Cambridge University Press (Paperback Edition * 56), 1962, pág. 67.

8 B. Russell, Logic and Knowledge, pág. 247; L. S. Stebbing, A Modern Introduction to Logic, Methuen, séptina edición,, 1950, pág. 146. 
de la significación implícita en aquellos argumentos. El error fundamental residiria en la confusión entre nombres y descripciones. Puesto que proposiciones como "El actual Rey de Francia es sabio" - razona Russell-- son significativas, o bien las expresiones que constituyen el sujeto gramatical se interpretan como nombres, debiendo postularse entonces la entidad de la cual es nombre $\longrightarrow$ bien no son nombres y entonces su significatividad, a reserva de explicarla, no implica la existencia de una entidad. ${ }^{9}$

La distinción entre nombres y descripciones tiene, por lo pronto, el mérito de haber limitado la validez de los argumentos en favor de entes ideales al caso particular de los nombres y, además, a una específica teoría -que Russell comparte- acerca de su significación. Examinemos ahora, en sus grandes rasgos, el análisis de las proposiciones cuyos sujetos son descripciones definidas. El primer paso consiste en reducir la descripción definida a una función proposicional. ${ }^{10} \mathrm{La}$ plausibilidad de esta reducción en relación al lenguaje ordinario se advierte en un ejemplo. Imaginemos que alguien dijera, en una circunstancia verosímil, la expresión "El hombre más gordo del mundo", y supongamos que admitiera no saber quién es, en realidad, el hombre más gordo del mundo. No obstante ello, sería perfectamente natural que agregara que debe, sin embargo, haber alguna persona o individuo que sea así. Tendríamos entonces una función proposicional: " $x$ es más gordo que cualquier otra persona", siendo el símbolo $x$ una variable individual. Si, en otra circunstancia, quisiéramos explicar lo que queremos decir con la descripción definida "El autor del Quijote", podríamos responder que es la persona que escribió el Quijote. De nuevo nos encontraríamos frente a una función proposicional: " $x$ escribió el Quijote". ${ }^{11}$ En esta reducción se trata de poner de relieve un hecho fundamental relativo a las descripciones, a saber, que se refieren a un individuo mediante caracteristicas, mediante predicados que, según los casos, se aplicarán o no a un individuo. Un nombre, por el contrario, consiste, según vimos, en una simple indicación. Y ésta sería, en último término, la razón por la que es posible que una descripción sea comprensible aun en el caso en que ignoremos al individuo al que se describe.

Ahora bien, cuando una descripción definida es el sujeto gramatical de una proposición, su análisis no se agota, claro está, en la reducción anterior. Porque si el sujeto fuese una función proposicional, entonces la sentencia no sería ni verdadera ni falsa, no sería una proposición; en tanto que las proposiciones cuyos sujetos gramaticales son descripciones serán, siempre, verdaderas o falsas. Veamos cómo es esto posible. Según Russell una pro-

- P. F. Strawson, "On Referring", recogido en Essays in Conceptual Analysis, MacMillan, 1956 , págs. $24-25$.

10 B. Russell, Introduction to Mathematical Philosophy, págs. $155-56$.

11 B. Russell, Logic and Knowledge, pág. 249. 
posición como "El actual Rey de Francia es sabio" afirmaría, prima facie, dos cosas: que existe un individuo que se caracteriza por esas propiedades y que ese individuo es, en este caso, sabio, o sea, una propiedad más. De manera que "El actual Rey de Francia es sabio" se descompone en: "El actual Rey de Francia existe y es sabio." 12 Veamos, ahora, cómo se analiza la afirmación de que existe un individuo con esa propiedad, es decir, cómo se analiza. el enunciado "El actual Rey de Francia existe" o cualquier otro de esa forma. Cuando a propósito de una descripción nos preguntamos por la existencia, lo que en primer lugar estaríamos preguntando es si existe un individuo que posee esas propiedades. Estaríamos haciendo una pregunta relativa a una función proposicional.13 En efecto, sabemos que en la expresión "El actual Rey de Francia" se encuentra una función proposicional; por consiguiente, el análisis de "El actual Rey de Francia existe" se convierte en una explicación de lo que quiere decirse cuando se afirma existencia en relación a una función proposicional. ¿Cómo se formula la pregunta acerca de la existencia cuando se trata de una función proposicional? Del siguiente modo: si existe un individuo tal que cuando en una función proposicional sustituimos la variable individual por el nombre del individuo -0 por una constante individual - Ia función proposicional se convierte en una proposición verdadera. De manera que cuando afirmamos que "El tal y cual existe", estaríamos afirmando que la función proposicional " $x$ es tal y cual" es verdadera cuando menos respecto de una $x$-siendo $x$ una variable individual. Otra manera de expresar lo mismo es decir que la función proposicional es algunas veces verdadera. ${ }^{14}$ Todo lo cual quedaría resumido en la fórmula (G $x) \phi x$-siendo $\phi$ un símbolo para designar propiedad en general.

Pero la afirmación de existencia tiene otro aspecto, a eaber, el de singularidad de referencia o denotación, que, en el lenguaje ordinario, se expresa en el uso que en estos casos tiene el artículo definido. ${ }^{15}$ Cuando afirmamos que "El vencedor de Jena es corso" o que "El autor del Quijote es español" estamos implicando que existe sólo un individuo que responde a estas descripciones. De manera que no sólo se afirma que existe un individuo con esos artibutos - primer aspecto de la afirmación de existencia- sino, además, que no es el caso de que haya, por ejemplo, dos individuos que respondan a la descripción. Porque es evidente que la explicitación de la primera parte de la afirmación de existencia es compatible con la existencia de varios indivi-

12 B. Russell, Logic and Knowledge, pág. 250; Introduction to Mathematical Philosophy, págs. 177-78.

13 B. Russell, Logic and Knowledge, pág. 232.

14 B. Russell, Logic and Knowledge, pág. 249; Introduction to Mathematical Philosophy, pág. 177 .

15 Que no es ésta la única manera de usar una sentencia de este tipo es evidente. "La ballena es un mamífero" expresa una proposición universal. Véase Stebbing, op. cit., pág. 149. 
duos que satisfagan la función proposicional -como lo ilustra el hecho de que se simbolice con un cuantificador existencial. Este segundo aspecto lo resume Russell diciendo que la función proposicional debe ser verdadera cuando más respecto de una $x$-siendo $x$ una variable individual. ${ }^{16}$ Lo que es igual a decir que cualquier otro individuo que satisfaga la función proposicional será idéntico al primer individuo del cual se afirma que satisface la función proposicional. Si simbolizamos los dos aspectos del análisis obtenemos lo siguiente: $(\exists x)[\phi x \cdot(y)(\phi y) y=x)]$. Con esto se concluye la explicación de la primera parte en que se descompuso el enunciado "El actual Rey de Francia es sabio". A estas alturas es fácil comprender cómo se interpretará la segunda parte, la que afirma, en este caso, que el actual Rey de Francia es sabio: estaríamos diciendo que el individuo del cual se dijo que él, y sólo él, posee los atributos mencionados en la descripción, tiene también este otro. Lo cual es equivalente a afirmar que no hay nadie que sea Rey de Francia y no sea sabio. Por tanto, la simbolización completa de una proposición de la forma de "El actual Rey de Francia es sabio", sería la siguiente: $(G x)[\phi x \cdot(y)(\phi y) y=x) \cdot \psi x]$-donde $\psi$ denota una propiedad en general. ${ }^{17}$ Otra manera de asentar lo mismo sería así: si "El actual Rey de Francia" ejemplifica una función proposicional - " $x$ es Rey de Francia"-y si el predicado "sabio" se predica del mismo individuo, de tal manera que tenemos otra función proposicional -a saber, " $x$ es sabio"- entonces obtenemos como resultado final la función proposicional compleja " $x$ es Rey de Francia y $x$ es sabio". En símbolos tendríamos: $(F x \cdot S x)$. Pero, como ya sabemos, en la proposición "El actual Rey de Francia es sabio" afirmamos la existencia de alguien que posee la propiedad, o las propiedades, presente en la descripción y en el último predicado; esto es, afirmamos que hay cuando menos un valor de la función proposicional compleja $(\mathrm{Fx} \cdot S x)$ que la convierte en una proposición verdadera. En forma equivalente: la función proposicional " $x$ es rey de Francia y $x$ es sabio" es a veces verdadera. Sin embargo, si dejáramos el asunto aquí no se garantizaría la condición de singularidad con respecto al primer predicado, pues si simbolizamos lo anterior tendriamos $(\mathbb{I} x)(F x \cdot S x)$ y un cuantificador existencial no garantiza singularidad; en cuanto al segundo predicado esta condición no interesa ya que no se afirma que no existe ningún otro individuo que sea sabio. Debemos agregar, entonces, que la función proposicional "si $x$ es Rey de Francia y $y$ es Rey

16 B. Russell, op. cit., pág. 249; op. cit., pág. 177.

17 Nos parece equívoco, sin embargo, decir que únicamente se trata de asignar un predicado más, ya que esto haria suponer que todos ellos cumplen la misma función. Lo cual es confuso. El rasgo común es que, en verdad, nos las habemos con predicados en ambos casos y en relación al mismo individuo; la distinción está en que la últíma propiedad se predica de alguien que ha sido identificado mediante predicados. Una indicación de esta distinción está en que la condición de singularidad sólo se establece en relación al primer predicado, el de la descripción definida. 
de Francia, entonces $y=x "$ es siempre verdadera. Con lo cual quedaría asegurada la condición de singularidad. Si unimos ahora ambas formulaciones obtenemos como resultado final lo siguiente: la función proposicional " $x$ es Rey de Francia y $x$ es sabio" es a veces verdadera y la función proposicional "si $x$ es Rey de Francia, y $y$ es Rey de Francia, entonces $y=x$ " es siempre verdadera. En resumen, pues, una proposición cuyo sujeto gramatical es unạ descripción definida afirmaría, en último análisis, tres cosas - pues, como vimos, la afirmación de existencia se subdivide en dos- que formuladas en lenguaje ordinario, sin acudir al lenguaje lógico de las funciones proposicionales, dirían así en relación al ejemplo "El actual Rey de Francia es sảbio": r) Cuando menos una persona es Rey de Francia (o si se prefiere: hay alguien que es Rey de Francia); 2) cuando más una persona es Rey de Francia (o si se prefiere: no hay más que una persona que sea Rey de Francia); 3) quienquiera que sea la persona que es Rey de Francia esa persona es sabia (o si se prefiere: no hay alguien que sea Rey de Francia y no sea sabio). ${ }^{18}$ Según Russell 1 ), 2) y 3) están implicados en la proposición inicial.

3) Con lo anterior se concluye el análisis de este tipo de proposiciones. Veamos, ahora, en qué situación nos coloca con respecto al problema inicial. Creemos que los dos aspectos fundamentales del anạ́lisis de Russell pueden caracterizarse como dos conversiones: en primer lugar, en relación al sujeto gramatical; en segundo lugar, la conversión de la proposición en un tipo de proposición existencial compleja. En cuanto al primer aspecto, sabemos que consiste en demostrar que esta clase de expresiones no pueden interpretarse como nombres; o dicho en forma más positiva, los que parecian ser nombres se descomponen en predicados y variables individuales, esto es, en funciones proposicionales. El mérito de esta conversión reside en que los símbolos o las palabras que se emplean para expresar su sentido no implican, por el mero hecho de ser significativós, la existencia de ese objeto individual que la expresión original parecía nombrar. En efecto, el peso de la referencià, como diría Quine, ${ }^{19}$ lo llevan ahora las variables individuales, en rigor variables individuales ligadas en el análisis final, que como es sabido, corresponden en el lenguaje ordinario a palabras como "algo", "alguien", "todo", etc. Ahora bien, es evidente que estas palabras no son nombres de individuos o particulares, no nombran un objeto individual; lo cual es equivalente a decir que su significación no implica la existencia de un determinado individuo. ${ }^{20}$

18 B. Russell, Introduction to Mathematical Philosophy, pág. 177.

19 W. O. Quine, "On What There Is", recogido en From a Logical Point of View, Harvard University Press, 1953, pág. 6.

20 De ahí que para Russell sólo tenga sentido afirmar, negar o cuestionar la existencia cuando se trata de una descripción. Si en un momento dado nos preguntamos, por ejemplo, si algo existe -y la pregunta es genuina_ entonces con toda seguridad el sujeto gramatical o aparente de la pregunta es una descripción ya que, en conformidad 
Cuando más podrá decirse, y ello es discutible, que se refieren a entidades en general, "... with a kind of studied ambiguity peculiar to themselves".21 El punto esencial es, en todo caso, que no son nombres de objetos particulares. En lo que toca a los predicados que complementan las funciones proposicionales, no es necesario argumentar que su significatividad no supone, en modo alguno, la existencia de un particular - puesto que su función no es la de indicar individuos; por lo demás, el argumento en favor de los entes ideales no se refería a los predicados. Así ninguno de los símbolos que emplea Russell en su paráfrasis de lo afirmado en las proposiciones cuyos sujetos gramaticales son descripciones, es un símbolo que pueda tomarse como un nombre. Por consiguiente no es posible aplicar el argumento de la significación para postular entes ideales. En cuanto a la segunda conversión, ésta permite que las proposiciones de este tipo sean siempre verdaderas o falsas. En efecto, si en una proposición de esta clase estamos, en realidad, afirman-

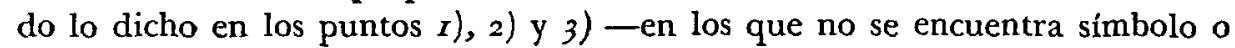
palabra cuya significación implique la existencia de un objeto particular- es obvio entonces que, por ejemplo, la proposición "El autor del Quijote es español" es falsa en el caso en que nadie haya escrito el Quijote, o en el caso en que más de una persona haya escrito el Quijote, o en el caso en que una persona, y sólo una, lo haya escrito pero esta persona no sea española. De manera que cuando no se cumple lo afirmado en el punto $x$ ) -que son los casos que nos interesan- la proposición resulta falsa. En símbolos tendríamos que la verdad de $\sim(\exists x) \phi x$ implica la verdad de $\sim(\exists x)[\phi x \cdot(y)$ ( $\phi y \supset y=$ $x) \cdot \psi x$ ]. Por tanto ya no será posible argumentar que si la proposición, por ser significativa, es verdadera o falsa, es necesario conceder la existencia de aquello a lo cual pretende referirse el sujeto gramatical. Porque de acuerdo con este análisis, la verdad o la falsedad de la proposición no depende únicamente de la aplicación o no aplicación del predicado "español" en el ejemplo antes citado, o "sabio" en "El actual Rey de Francia es sabio" -como ocurriría si fuesen proposiciones de la forma sujeto-predicado. Por consiguiente, el simple reconocimiento de que la proposición, por ser significativa, es siempre "verdadera o falsa" no obliga a admitir entes ideales. Para decidir, es menester saber si el punto 1 ) se cumple o no se cumple. De esta manera es posible mantener que las proposiciones de esta clase son significativas y siempre "verdaderas o falsas" sin que haya necesidad de aceptar la existencia ideal de un ente. La paráfrasis de Russell no sacrifica ni el

con sus tesis, si una palabra es un nombre, existe aquello de to cual es un nombre. Por consiguiente, si es un nombre no cabe dudar, cuestionar, acerca de la existencia de aquello a lo cual se refiere. Si lo hiciésemos, incurriríamos en un absurdo parecido a preguntar, "¿Esto que existe, existirá?" Véase, B. Russell, Introduction to Mathematical Philosophy, págs. 178-79; Logic and Knowledge, pág. 252 sigs.

21 W. O. Quine, op. cit., pág. 6. 
principio del tercio excluso ni la significación de proposiciones como "La montaña de oro no existe" o "El actual Rey de Francia es sabio". Queda así refutada la pretensa "necesidad" del argumento en sus dos presentaciones. Entia non sunt multiplicanda praeter necessitatem.

Volvamos al ejemplo de "La montaña de oro no existe". Si alguien sostiene que dicha proposición es verdadera porque no existe espacio-temporalmente una montaña de oro, no por ello admite, según Russell, que existe aquello a lo cual se refiere el sujeto, cayendo así en todas las complicaciones conocidas; estará sosteniendo que el punto $I$ ) no se cumple. $O$ sea que la fórmula que va precedida por $\sim(\exists x)$ es verdadera. La proposición es significativa y verdadera sin necesidad de otro ente. Si alguien sostiene que "El actual Rey de Francia es sabio" es falsa porque hoy día nadie reina en Francia, tampoco estará obligado a postular un ente por haber asignado un valor de verdad. Podrá decir que es falsa y significativa porque no se cumple el punto $x)$. Estará diciendo que $\sim(\mathrm{G} x)[\mathrm{F} x \cdot(y)(\mathrm{F} y \supset y=x) \cdot S x]$ es verdadera.

Pero supongamos que alguien admite la corrección de la paráfrasis de Russell y sostiene, no obstante, que "La montaña de oro existe" es una proposición verdadera. Es decir, sostiene que hay un valor de la variable individual, y sólo uno, que convierte a la función proposicional compleja en una proposición verdadera. Supongamos, además, que se le demuestra que espacio-temporalmente no existe, ni ha existido, una montaña de oro e imaginemos que replicara que conviene en ello, pero que él se refiere a la montaña de oro ideal o lógica. Es claro que, en una situación así, la Teoría de las Dẹscripciones es impotente. Si para postular ese ente lógico o ideal no acude a los argumentos que se basan en tesis acerca de la significación y asignación de valores de verdad, la Teoría de las Descripciones es perfectamente neutral. Lo único que resta, entonces, es exigirle otras pruebas en favor de ese ente ideal y objetarlas, si cabe, con otros métodos. Ahora bien, si la Teoría de las Descripciones es neutral en una situación como la anterior, ello indica que su validez en cuanto análisis de lo que se afirma en proposiciones cuyos sujetos son descripciones definidas, no presupone, en manera alguna, la aceptación de un único modo de existencia, la existencia espacio-temporal, por ejemplo; el cuantificador existencial no debe interpretarse como indicando existencia espacio-temporal. Pues si alguien, basado en argumentos diferentes a los que hemos examinado, postula entes ideales, estará sosteniendo que el valor de la variable individual no es espacio-temporal y en ese caso para él la proposición será verdadera aun aceptando la paráfrasis de Russell. Y la razón última de esto es que para Russell afirmar que algo existe es simplemente afirmar que la función proposicional es a veces verdadera. Si se afirma, para tomar un ejemplo de Quine, la existencia de la raiz cúbica de 27 , existencia no tiene aquí una connotación espacio-temporal y, sin embargo, 
podemos aplicar el análisis de Russell para explicitar el significado de la proposición.22

Se corrobora, entonces, lo que dijimos páginas atrás, a saber, que la manera como Russell refuta esos argumentos no es ni objetando el principio del tercio excluso ni cuestionando la teoría de la significación de los nombres. Lejos de rechazarla, la utiliza para explicar la significación de los nombres, implicándose, según vimos, que si los sujetos gramaticales de esas proposiciones fuesen nombres nos encontraríamos desarmados frente al primer argumento en favor de los entes ideales. Queda en claro, pues, que el hecho de que Russell sostenga esa teoría de la significación es cuando menos uno de los motivos esenciales para proponer la Teoría de las Descripciones; parte de la plausibilidad, por así decirlo, de la Teoría de las Descripciones está en relación directa con la corrección de esas tesis acerca de la significación de los nombres. Porque se supone correcta, la Teoria de las Descripciones se presenta como la alternativa para refutar ese argumento. Es evidente, por lo mismo, que si es posible invalidar ese argumento demostrando la incorrección de la tesis acerca de la significación, la Teoría de las Descripciones perderá importancia, o será de plano innecesaria, cn cuanto instrumento para cerrar ese camino que conduce hacia los entes ideales. Es en este sentido que dijimos que parte de su plausibilidad depende de la corrección de la tesis acerca de la significación de los nombres. Pero si se demuestra que pierde plausibilidad en este sentido, no por ello se demuestra que el modelo de traducción que ofrece la Teoria de las Descripciones sea erróneo. Con un poco de más precisión: según se dijo, los rasgos esenciales del análisis de Russell son la conversión de los sujetos gramaticales en predicados y la conversión de la proposición en una proposición existencial compleja. Pues bien: Russell podria haber propuesto la primera conversión simplemente advirtiendo que con los sujetos gramaticales de esas proposiciones nos referimos mediante predicados. Decir esto no supone una tesis especial acerca de la significación de los nombres; la verdad de la tesis de que en esos casos nos referimos vía predicados, no depende de la verdad de una tesis particular acerca de la significación de los nombres. En cuanto a la segunda conversión, lo que podríamos llamar el aspecto existencial del análisis, ello es aún más evidente: proponer que en esas proposiciones se afirma, por ejemplo, el punto $I$ ) —que es el más importante- no implica una tesis relativa a la significación de los nombres. Vemos, entonces, que si la crítica a esa teoría de la significación de los nombres - teoría que Russell de hecho acepta - fuese correcta, lo único que habría que abandonar sería la idea de que la Teoría de las Descripciones es la alternativa para refutar el primer argumento. Estando así las cosas, no

22 W. O. Quine, op. cit., pág. 3. Nos es imposible aquí examinar a fondo el problema, el cual nos llevaria hasta la Teoría de los Tipos. Véase Stebbing, op. cit., pág. 162 y $M$. Black, op. cit., 
se incurriría en una inconsistencia si se aceptara la crítica de la teoría de la significación de los nombres y a la vez se mantuviese el análisis de Russell en sus dos aspectos esenciales. Ahora bien, con el análisis de Russell es posible objetar también el segundo argumento en favor de los entes ideales; lo cual no es posible acudiendo únicamente a la crítica de la teoría de la significación de los nombres. Por la sencilla razón de que el segundo argumento no se basa directamente en ella. Los puntos fundamentales del segundo argumento son la aplicación irrestricta del principio del tercio excluso si son significativas, y el reconocimiento de que esas proposiciones son de la forma sujeto-predicado. Lo cual es muy distinto a decir simplemente que si son significativas se refieren a algo. En el segundo argumento no se apela, al menos explicitamente, a una explicación de la manera como esas expresiones son significativas; se apela a una consecuencia del hecho de que sean significativas - sin pronunciarse acerca de la explicación- y a una tesis acerca de su forma lógica. Por tanto las objeciones deben ser diferentes. Russell al demostrar que los sujetos no son nombres, niega que tengan la forma sujeto-predicado y el aspecto existencial de su análisis muestra que, sin embargo, son siempre verdaderas o falsas -refutando, así, también el segundo argumento. Por tanto sería lógicamente posible rechazar el primer argumento mediante una crítica a la teoría de la significación -restándole una cierta plausibilidad a la Teoría de las Descripciones-y rechazar el segundo argumento siguiendo a la Teoría de las Descripciones. Pero si se quiere rechazar el segundo argumento en una forma distinta a como lo hace la Teoría de las Descripciones - sosteniendo, por ejemplo, que no siempre se aplica, por las razones que sea, el principio del tercio excluso- se tendrá que modificar, en este caso necesariamente, el modelo del análisis de Russell. Si esas razones fuesen correctas, la Teoría de las Descripciones sería inadecuada en cuanto análisis general de proposiciones como "El actual Rey de Francia es sabio".

4) La crítica de Strawson ${ }^{23}$ a los argumentos en favor de los entes ideales consiste en atacar, en primer lugar, la teoría de la significación implícita $y$, en segundo lugar, la tesis de que las sentencias son siempre verdaderas o falsas. Strawson comienza trazando las siguientes distinciones. Por una parte ( $\left.\begin{array}{ll}A & 1\end{array}\right)$ una sentencia; $\left(\begin{array}{lll}A & 2\end{array}\right)$ un uso de una sentencia; $\left(\begin{array}{ll}A & 3\end{array}\right)$ el acto de decir o proferir una sentencia (an utterance of a sentence). $\mathrm{Y}$ por la otra entre $\left(\begin{array}{ll}B_{1} & 1\end{array}\right)$ una expresión; $\left(\begin{array}{l}B_{2} \\ 2\end{array}\right)$ un uso de una expresión; $\left(\begin{array}{l}B_{3} \\ 3\end{array}\right)$ el acto de decir o proferir una expresión (an utterance of an expression). Si nuevamente consideramos "El actual Rey de Francia es sabio", vemos que es

23 P. F. Strawson, op. cit.; Introduction to Logical Theory, Methuen, 1952; véase el capítulo 6 y en especial págs. 184 sigs. Naturalmente lo que sigue no pretende ser un resumen ni siquiera incompleto del articulo de Strawson y de lo que en su libro afirma sobre el problema. Simplemente destacaremos algunas de sus tesis. 
posible que haya sido dicha o proferida en Francia durante diversos reinados; se dirá, entonces, que la misma sentencia fue proferida o dicha en diversas circunstancias. Es en este sentido que Strawson usa $\left(\begin{array}{l}A \\ 1\end{array}\right)$. Ahora bien, la misma sentencia puede ser usada en diferentes ocasiones para referirse a diferentes individuos: si dos personas la usaron, pongamos por caso, para referirse a Luis XV, habrán hecho el mismo uso de la misma sentencia; en tanto que si una persona durante el reinado de Luis XIV la usó para referirse a ese Rey y otra durante el reinado de Luis XV la usó para referirse a este otro Rey, habrán hecho un uso diferente de la misma sentencia. En el primer caso se dirá que han ejecutado dos actos distintos de proferir o decir la misma sentencia en un uso igual de ella. ${ }^{24}$ De donde se desprenden dos cosas: en primer lugar es obviamente posible que un determinado uso de la sentencia resulte en una proposición o enunciado verdadero, en tanto que un uso distinto de la misma sentencia resulte en una proposición o enunciado falso. En segundo lugar $-\mathrm{y}$ como consecuencia de lo anterior- es absurdo sostener que la sentencia se refiere a una persona en particular, puesto que, como escribe Strawson, “... the same sentence may be used at different times to talk about quite different particular persons". ${ }^{25}$ Sólo de un uso particular de la sentencia podemos decir que se refiere a una persona en particular. Algo parecido, pero no igual, puede decirse de una expresión $(B$. 1), por ejemplo, "El actual Rey de Francia". Una expresión se usa ( $B$ 2) para referirse a una persona en particular y, naturalmente, puede tener diversos usos, referirse a diferentes personas. Por tanto, tampoco aquí cabe decir que la expresión refiere: "'Mentioning' or 'referring' is not something an expression does; it is something that someone can use an expression to do." 28 Dejando a un lado puntos menores, lo anterior indica que sería un error mezclar afirmaciones relativas a sentencias y expresiones $\left(\begin{array}{llll}A & 1\end{array}\right)$ y $\left(\begin{array}{ll}B & 1\end{array}\right)$ con afirmaciones relativas a los usos de sentencias y expresiones $\left(\begin{array}{lll}A & 2\end{array}\right)$ y $\left(\begin{array}{l}B \\ B\end{array}\right)$. De la significación, por ejemplo, sólo es posible hablar, según Strawson, en relación a una sentencia o expresión; de la verdad o la falsedad, sólo en relación al uso de la sentencia; de la referencia, en relación al uso de la sentencia o de la expresión. Así, dar el significado de "El actual Rey de Francia" es más o menos equivalente a suministrar las directrices generales relativas a su uso para referirse a objetos o personas particulares. ${ }^{27}$ No consiste, pues, en hablar de la persona' u objeto al que quizá se refiera en un uso específico. Entonces la significación de una expresión no se identifica con ningún objeto al cual pueda referirse en una ocasión determinada. ${ }^{28}$ En

24 P. F. Strawson, "On Referring", págs. 27 sigs.

25 P. F. Strawson, op. cit., págs. 28-29.

26 P. F. Strawson, op. cit., pág. 29.

27 P. F. Strawson, op. cit., pág. 30.

28 P. F. Strawson, op. cit., pág. 30 . 
cuanto a "El actual Rey de Francia es sabio", dar su significado también consiste en parte en aclarar las directrices generales para usarla en aserciones que pueden ser verdaderas o falsas. Por tanto, tampoco debe identificarse con lo que se afirma en una circunstancia particular. ${ }^{29}$ En términos generales, entonces, el significado de una expresión o sentencia de este tipo es el conjunto de hábitos, convenciones y reglas para usar la expresión referencialmente y para usar la sentencia en afirmaciones. ${ }^{\mathbf{3 0}}$

Ahora bien, el uso de una sentencia puede ser genuino o espurio (o secundario). ${ }^{\text {a1 }}$ Será genuino si, por ejemplo, una persona durante el reinado de Luis XV hubiese dicho "El actual Rey de Francia es sabio"; espurio si en 1964 alguien hubiera dicho la misma sentencia. Que sea espurio (o secundario) es algo relativo al uso de la sentencia y no pone en cuestión su significatividad; en el caso en que la referencia falle, se dirá que la sentencia ha sido usada espuriamente y no que la sentencia carece de significado, pues para que sea significativa es suficiente, nos dice Strawson, que sea posible describir las circunstancias en las cuales su uso dará por resultado un enunciado verdadero o falso.32 Lo cual es obviamente posible en el caso de "El actual Rey de Francia es sabio". En suma, la significación de una sentencia de este tipo no exige que, cada vez que se use, haya algo a lo cual se refiera. ${ }^{33}$ No es posible, por consiguiente, argumentar que si es significativa, es necesario que siempre se refiera a algo en particular, abriéndose una de las puertas a los entes ideales. El error tanto de Russell como de quienes favorecen ese argumento sería, en definitiva, el haber mezclado la significación con la referencia; no haber distinguido $\left(\begin{array}{ll}A_{1}\end{array}\right)$ y $\left(\begin{array}{l}B_{1} \\ 1\end{array}\right)$ de $\left(\begin{array}{ll}A_{2}\end{array}\right)$ y $\left(B_{2}\right)$. La Teoría de las Descripciones, en este punto, pretende resolver un seudo-problema.

Ahora, cuando una sentencia está usada espuria o secundariamente, Strawson sostiene que no es ni verdadera ni falsa. Lo cual, en su esquema, es igual a decir que si "El actual Rey de Francia es sabio" es significativa, no se sigue necesariamente que los usos de la sentencia darán siempre por resultado proposiciones o enunciados verdaderos o falsos; su uso decidirá si es verdadera o falsa o ninguna de las dos cosas. Con lo cual se impide el planteamiento del segundo argumento en favor de los entes ideales sin necesidad de objetar que no se trata de una sentencia cuya forma es la de sujetopredicado. Nótese, sin embargo, que la distinción entre significación de una sentencia y uso particular de una sentencia en manera alguna implica, por sí sola, que cuando falla la referencia la sentencia no es ni verdadera ni falsa.

29 P. F. Strawson, op. cit., pág. zo.

30 P. F. Strawson, op. cit., pág. $3^{1}$.

31 Aquí atenderemos únicamente a un uso espurio; aquel en que se pretende seriamente referirse a algo o a alguien. No se tocará el problema de esos usos en contextos de ficción, por ejemplo.

32 P. F. Strawson, op. cit., pág. 35; Introduction to Logical Theory, pág. 185 .

33 P. F. Strawson, Introduction to Logical Theory, pág. 185 . 
De lo uno no se sigue lo otro. Podría aceptarse la distinción y mantenerse que cuando en un uso particular falla la referencia, el resultado es una proposición falsa. Lo único a que compromete la distinción es a sostener que no es necesario suponer otra referencia a algo ideal para explicar la significatividad de la sentencia; si aceptamos la distinción, la sentencia es significativa sin suponer algo al cual se refiera. Pero quedamos en libertad de decir que es falsa. De manera que si Strawson piensa que en un uso espurio la sentencia no es ni verdadera ni falsa, tendrá que suministrar otras razones. Admitir la distinción, en suma, es conceder que el resultado de un uso de la sentencia no afecta la significatividad de la misma - lo cual no quiere decir que haya usos que no sean ni verdaderos ni falsos. No hay, pues, que confundir el hecho de que una sentencia no es susceptible de ser verdadera o falsa- los valores de verdad no se aplican a la sentencia - con el hecho de que no es ni verdadera ni falsa en un uso determinado. Ahora bien, para sostener que en un uso espurio la sentencia no es ni verdadera ni falsa hay que rechazar la tesis de que en los usos de la sentencia se afirma la existencia única del sujeto, es decir, los puntos I) y 2) del análisis de Russell. Pero antes de examinar las razones de Strawson es conveniente recordar que Russell quedaría en libertad - si Strawson se limitase a la primera distinción, la relativa al significado y a la referencia- de aceptarla y mantener, al mismo tiempo, su análisis que convierte a todas las proposiciones en verdaderas o falsas sin por ello incurrir en ninguna inconsistencia. En ese caso, según ya se apuntó, su teoría sería innecesaria para rechazar uno de los argumentos en favor de los entes ideales. Pero la validez de su análisis quedaría intacta. Y, correlativamente, la primera distinción de Strawson podría ser correcta sin que lo fuesen sus razones para pensar que cuando se usa una sentencia de ese tipo no se afirman los puntos I) y 2) de la paráfrasis de Russell.

Strawson sostiene que en lugar de afirmarse se presuponen. Según esto, cuando se afirma "El actual Rey de Francia es sabio" se presupone que existe un hombre, y sólo uno, que reina en Francia. La traducción de su definición de presuposición dice así: " $S$ presupone $E$ " se define de la siguiente manera: "La verdad de $S^{\prime}$ es una condición necesaria de la verdad o falsedad de $S$ ". ${ }^{34}$ De modo que si $S^{\prime}$ no es verdadera, $S$ no es ni verdadera ni falsa. Si en 1964 alguien afirma que "El actual Rey de Francia es sabio", la sentencia no expresará ni un enunciado verdadero ni un enunciado falso, por no ser verdadero el enunciado presupuesto -aun cuando crea que está diciendo algo

34 P. F. Strawson, "A Reply to Mr. Sellars", Philosophical Review, vol. 63, 1954, pág. 216; Introduction to Logical Theory, pág. 175. Acerca de las diferencias entre las posiciones de Frege y Strawson sobre este punto y en lo relativo a algunas dificultades de la definición de Strawson, véase Max Black, "Presupposition and Implication", recogido en su libro, Model and Methaphors, Cornell University Press, 1962, págs. 48 sigs. 
verdadero. ${ }^{35}$ De manera que si $S^{\prime}$ fuese una condición necesaria sólo de la verdad de $S$, sería contradictorio afirmar $S$ y la negación de $S^{\prime}$ - como sucedería según el análisis de Russell; en tanto que afirmar $S$ y la negación de $S^{\prime}$, si $S^{\prime}$ es condición necesaria de la verdad o falsedad de $S$, no dará por resultado una contradicción, sino otra clase de absurdo lógico. Strawson piensa que esta forma de plantear las cosas refleja con mayor fidelidad la manera como estas sentencias se emplean en el lenguaje ordinario; y, en verdad, ésta es la razón esencial (si no única) que ofrece en apoyo de su teoría de la Presuposición en lo que toca a este tipo de sentencias. Porque si ésta no fuese la razón, la discusión con Russell se plantearía en un vacío de problemas y no se sabría cuáles son los criterios con los cuales tenemos que elegir entre ambos. Pues, como hemos visto, ambas teorías son capaces de responder al segundo argumento $y$, por tanto, esto no puede utilizarse como criterio de elección. La ventaja que Strawson reclama para la Presuposición es que además de resolver todos los problemas que la Teoría de las Descripciones pretende solucionar, refleja mejor el lenguaje ordinario. Para apoyar la idea de que la teoría de la Presuposición es una versión más fiel de lo que ocurre en el lenguaje ordinario, Strawson acude, naturalmente, a ejemplos. Veamos uno de ellos. Si alguien, en 1964 , nos dijera, con toda seriedad, que el actual Rey de Francia es sabio, Strawson piensa que no diriamos que no es cierto; y que si nos preguntara si lo que dijo es verdadero o falso, responderíamos que ni lo uno ni lo otro, que la cuestión de la verdad o de la falsedad no se plantea - precisamente porque hoy día nadie reina en Francia. En lugar de asignar valores de verdad, trataríamos de explicarle que se encuentra en un equívoco. De manera que al decirle que hoy día nadie reina en Francia, no estaríamos contradiciendo el enunciado, sino, más bien, dando una razón por la cual la verdad o la falsedad no se plantea. ${ }^{36}$ Llegamos así a la situación que la definición de Presuposición pretende codificar. La corrección de la teoría de la Presuposición, en cuanto reflejo del lenguaje ordinario, la prueba Strawson siempre con situaciones análogas: si alguien afirma $S$ y otra persona sabe que $S^{\prime}$ no es verdadera, la segunda persona, si le preguntan si $S$ es verdadera o falsa, rehusará asignar un valor de verdad a $S$.

Sería absurdo negar que hay contextos que ejemplifican la teoría de Strawson; sería igualmente erróneo pensar que su análisis es el más adecuado en cualquier situación, pues él mismo ha reconocido en escritos posteriores que hay excepciones. ${ }^{37}$ Sin embargo, hay que señalar que aun cuando Strawson -y no es el caso- tuviese absoluta razón, en el sentido de que su teoría

35 Strawson aclara explícitamente que la relación de presuposición no debe interpretarse en términos de 'creencia'. En lo tocante a este punto y al papel que le asigna a la creencia de que $S$ ' es verdadera, véase la "A Reply to Mr. Sellars", págs. 216-217.

36 P. F. Strawson, “On Referring”, pág. 34 .

37 P. F. Strawson, "A Reply to Mr. Sellars", págs. 225 sigs. 
de la Presuposición "reflejara" siempre con mayor precisión el uso de esas sentencias en el lenguaje ordinario, el análisis que lleva a cabo Russell de la afirmación de existencia no se afectaría. Es decir, si Strawson tuviese razón, "El autor del Quijote existe" no formaría parte de lo que se afirma —o del análisis, si se prefiere-.de "El autor del Quijote es español", pero no se habría dado una sola razón en contra de la manera como Russell interpreta la afirmación de existencia. Cuando se afirma existencia el análisis de Russell sería el adecuado. Ahora bien, la Teoría de las Despripciones no se aplica solamente a proposiciones como "El autor del Quijote es español" - sino también a proposiciones como "El autor del Quijote existe"; por tanto cometeríamos una equivocación si sostuviésemos que la aceptación de la teoría de la Presuposición supone un repudio total al análisis de Russell. Con lo cual se limitan considerablemente los alcances de la crítica de Strawson. Por último cabe advertir que el criterio - reflejo del lenguaje ordinariocon el cual se hos invita a elegir entre Presuposición y Teoría de las Descripciones, en relación, no lo olvidemos, únicamente a sentencias como "El actual Rey de Francia es sabio", podrá ser, desde luego, razonable, pero de ninguna manera es el único. Por consideraciones de otra indole puede ser conveniente que todas las proposiciones sean verdaderas $\mathrm{O}$ falsas. $\mathrm{Y}$ entonces la Teoría de las Descripciones sería un instrumento adecuado. Pero esto sería entrar en otro problema. En todo caso, lo que no es posible rechazar es que la teoría de la significación propuesta por Strawson es, en sus grandes líneas, verdadera.

Alejandro Rossi 